\title{
A QUESTÃO SOCIAL, O TRABALHO E O ESTADO: visões das elites parlamentares brasileiras
}

\author{
Sonia Ranincheski*
}

Resumo: A questão social - como uma aporia e potencial crise de legitimidade do sistema capitalista atual - tem mobilizado o pensamento sociológico e outros campos, como o político e o econômico. O presente artigo é uma análise dos discursos das elites parlamentares brasileiras relativos a projetos de leis trabalhistas apresentados na Câmara de Deputados na emergência do capitalismo do século XX. Foram analisados 73 discursos dos deputados brasileiros e 4.490 projetos presentes em uma década de plenário. Demonstra-se que o tema da questão social, mais especificamente o do trabalho, foi entendido no campo da política parlamentar como uma dimensão relacional, com abordagens sobre o papel do Estado, o modelo econômico e as movimentações sociais.

Palavras-chave: questão social, Estado, elites parlamentares.

\section{Introdução}

Nada mais atual do que a discussão da chamada questão social. As proposições levantadas por Robert Castel, Jacques Donzelot e Pierre Rosanvallon inspiram os estudos sobre a questão social como crise do século XXI ou como renovação de uma questão permanente no capitalismo. Para eles, não existe o social como uma substância independente que paira sobre a mente das pessoas e ronda a sociedade, independente do real em termos do político, do econômico e do cultural.

* Professora adjunta do Centro de Pós-Graduação e Pesquisa sobre as Américas (CEPPAC) da UnB. soniaran@unb.br

Artigo recebido em 13 abr. 2005 e aprovado em 21 jun. 2005. 
Para esses autores, é necessário pensar os problemas sociais sob o ponto de vista relacional e histórico. Eles advertem para os equívocos de se reduzir à questão social a questão dos excluídos, como sinônimo de pobres e de vitimização social. Deve-se analisar o tema de acordo com as condições de uso das riquezas produzidas socialmente e com os choques societários decorrentes de visões diferentes sobre essa riqueza produzida. A questão social é, neste caso, um tema político e da política. Atualmente, portanto, se a questão social pode ser entendida como um "déficit de cidadania" e não somente na perspectiva da exclusão econômica, ainda pode ser considerada como uma questão do trabalho, isto é, como uma categoria de exclusão ou inclusão na estrutura social. ${ }^{1}$

Parece pertinente, neste sentido, perguntar: Por que elites políticas parlamentares incorporam nos seus discursos o tema da questão social? Por que incorporam na sua agenda temas como reformas sociais? Tendo como referência essas questões, este trabalho discute quais são os sentidos possíveis de serem encontrados nos discursos dessas elites políticas brasileiras quando se referem ao tema da questão social. Discute-se como a questão social esteve presente na política brasileira, especificamente, entre os parlamentares da Câmara Federal entre os anos de 1904 a 1914 (conjuntura de emergência do capitalismo industrial no país). ${ }^{2}$

As relações políticas da sociedade, o papel do Estado, a justiça, o trabalho, a pobreza e a miséria fazem parte da discussão sobre a questão social. Robert Castel (1998, p. 30), ao conceituar a questão social como uma aporia, destaca como parte do termo as tensões existentes entre coesão e fratura social. $\mathrm{O}$ conceito põe em xeque a capacidade de manter intactas as relações de interdependência em uma dada sociedade. A questão social teria sido historicamente inaugurada como sendo uma questão do pauperismo, uma vez que o fenômeno da miséria questionava o conjunto da sociedade.

De acordo com Castel (1998, p. 41), “a questão social pode ser caracterizada por uma inquietação quanto à capacidade de manter a coesão de uma sociedade", não estando somente ligada à dimensão 
econômica. Com base nessa definição de Robert Castel, no sentido de aporia, pelos menos duas visões empíricas podem ser problematizadas.

A primeira visão é aquela que considera a questão social relacionada à condição ocupada pelo indivíduo na escala de sobrevivência e aponta para soluções de tipo assistencialista. As políticas de mínimos necessários - tais como saúde e educação estão, quase sempre, associadas a essa visão. Tal concepção parece exigir explicações para a existência da miséria, de suas causas e de seus agentes definidores. Na passagem do século XIX para o XX, conjuntura denominada de belle époque, confrontam-se aqueles que pensam a pobreza como digna e natural e uma outra corrente, defensora da pobreza como resultado de má conduta (Morell, 2002).

A segunda visão insere, na questão social, temas como trabalho, suas condições e regulamentação, e os salários. Em alguma medida, tal perspectiva pode se distanciar das políticas assistencialistas. $\mathrm{O}$ trabalho é a categoria identificadora do lugar do sujeito na sociedade, pois fora dele não haveria condições de inclusão. A instituição do livre acesso ao trabalho representou uma revolução jurídica tão importante quanto a revolução industrial, nas palavras de Robert Castel (2000). A mesma burguesia que levou séculos para obrigar os operários a se submeter a 15, 16 horas de trabalho, é levada, no final do século XIX, a aceitar a redução dessa jornada, com vistas a manter a força de trabalho e as garantias de ordem social. Marx (2002, p. 555) salienta que a liberdade que favorecia as empresas era demasiado forte, demasiado selvagem para os que podiam apenas suportá-la.

A liberdade e o individualismo triunfantes da belle époque comportavam uma face sombria: a individualidade negativa de todos aqueles que se encontravam sem vínculos e sem suportes, privados de qualquer proteção e de qualquer reconhecimento. Os sujeitos integrados tornaram-se vulneráveis, particularmente em razão da precarização das relações de trabalho, e as vulnerabilidades passaram a oscilar cotidianamente para aquilo que se chama de exclusão (Castel, 2000, p. 32). No entanto, em larga medida, era recorrente, no contexto 
do começo do século $\mathrm{XX}$, tratar o sintoma antes da causa, reduzindo o essencial da questão social a uma questão de polícia e à repressão à vagabundagem.

À visão de Robert Castel é possível somar o estudo de Pierre Rosanvallon. Este autor não trata especificamente da questão social, mas de como a sociedade e o Estado constroem mecanismos para incorporar os benefícios para a maior parcela da população, uma vez que os riscos e o pauperismo eram objetos de preocupação, inclusive dos liberais. Rosanvallon (1998) retoma a idéia de contrato social e solidariedade de Durkheim para explicar a emergência de um Estado preocupado com as questões sociais. Conforme seu estudo, no início da sociedade moderna, a discussão baseada na idéia do risco e das possibilidades de prevenir redundou na criação da instância do seguro social mantido pelo Estado. Parece interessante notar que, para o século XXI, o mesmo autor defende que seja modificada a idéia de seguro, do ponto de vista material, e seja recriada a noção de solidariedade.

Para Rosanvallon (1991), apesar de prevalecer a função do Estado como monopólio legítimo do uso da força, outras formas de Estado foram sendo engendradas, tais como Estados dentro de Estados. Até os anos 30, sobretudo, era possível encontrar pelo menos três formas de atuação do Estado: o Leviatã, a potência soberana que regula a ordem interna, administra a justiça e gera a segurança nacional; o Estado instituidor do social, como o agente de organização e de constituição da sociedade, o produtor da identidade coletiva que substitui os antigos grupos intermediários; e o Estado providência, que é essencialmente o Estado protetor a gerir uma sociedade do seguro, na qual os riscos e as responsabilidades são socializados.

Quando se pergunta por que as elites políticas parlamentares incorporaram nos seus discursos o tema da questão social e possíveis reformas sociais e questões sociais, pelo menos duas razões podem ser levantadas, as quais não são necessariamente excludentes. A primeira, seria a necessidade de responder aos conflitos originados 
de uma situação não controlada ou a pressões sociais; a segunda, seria a possibilidade de antecipar possíveis distúrbios sociais ou mesmo necessidades de desenvolvimento para o próprio sistema.

Parte-se da concepção de Claus Offe, para quem é possível haver a combinação das duas razões. Segundo Offe (1984), pode haver concepções políticas reativas - como forma de resguardar interesses - e concepções políticas nas quais estão presentes interesses imperativos do processo de produção capitalista - não ligados às exigências da classe operária, mas às exigências funcionais do sistema produtivo. Não se trata apenas de um controle da ordem, embora seja um elemento recorrente nos discursos políticos. Claus Offe (idem, p. 36) defende a tese de que, para a explicação da trajetória evolutiva da política social, precisam ser levadas em conta como fatores causais concomitantes tanto as "exigências" quanto as necessidades, tanto os problemas de integração social quanto os problemas de integração sistêmica. Neste sentido, este autor amplia a discussão para além da proposição de implementação por etapas dos direitos (e o social está incluído aí) defendida por Marshal (1967).

A política social, assim sendo, teria funções de legitimação e acumulação, e faria parte de um conjunto de instrumentos colocados ao alcance de elites que estivessem no poder político. Entre as possibilidades mais radicais de representação instrumental do Estado - seja como agente neutro de garantia de contrato social, seja como um comitê executivo de classe dominante, ao gosto marxista - situase a perspectiva do Estado como agente de intervenção via políticas sociais e como compensador dos efeitos das desigualdades de mercado sobre os cidadãos.

No que concerne ao Estado e seu papel, apesar de distintas visões - a maximalista (maior presença do Estado) ou a minimalista (menor presença do Estado) - a gestão estatal está relacionada à presteza em articular interesses divergentes localizados na sociedade. Se, como afirma Weber (1984, p. 1.046), podem-se encontrar dificuldades para analisar as múltiplas relações que se criaram entre o Estado e o complexo social, isso não descarta a possibilidade de 
encontrar interconexões entre o mundo real da economia e o da política. É possível, portanto, nas discussões das elites políticas parlamentares, elementos de sentido sobre como esse Estado poderia ou deveria se inserir no tocante às questões sociais.

O presente artigo procura mostrar como as discussões sobre a questão social eram conduzidas como temas da política e não somente como "caso de polícia", mesmo que não se possam encontrar "políticas sociais" tais como são entendidas atualmente. Para tanto, foram lidos os discursos dos deputados presentes em 73 sessões legislativas e 4.490 projetos apresentados na Câmara dos Deputados. Para a análise deste vasto material, foi levada em consideração a existência de um campo político plural, no qual as elites políticas parlamentares não se configuraram em um bloco homogêneo de idéias e interesses (Hagopian, 1996, p. 19). ${ }^{3}$

\section{Os discursos, os projetos e os parlamentares brasileiros}

No Brasil, as elites parlamentares, entre os anos de 1904 e 1914, ao formularem idéias e projetos relativos à questão social, relacionaram o tema (questão social) à esfera do trabalho e do Estado. Dito de outro modo, a questão social esteve relacionada às condições de trabalho como assunto da máquina administrativa do Estado.

Analisando os projetos apresentados à Câmara Federal nesse período, pode-se perceber que havia uma predisposição para assuntos relativos ao Estado, como se observa na Tabela 1.

No tema dos funcionários do Estado: assuntos individuais (31,4\% dos projetos), o objetivo era conceder algum benefício para um indivíduo ligado ao Estado (como trabalhador) ou a seus familiares (viúva ou filhos), tais como férias, licenças-saúde ou pensões. Esses projetos não pressupunham uma norma geral, mas sempre tratavam de situações individuais, obrigando a Câmara a discuti-los caso a caso. Com relação ao tema dos projetos relativos a Funcionários 


\section{Tabela 1- Temas de projetos apresentados na Câmara de Deputados do Brasil - 1904 a 1914}

\begin{tabular}{l|r|r}
\hline Temas de projetos & \multicolumn{1}{|c|}{$\mathbf{N}^{\mathbf{0}}$} & \multicolumn{1}{c}{$\%$} \\
\hline Assistência & 7 & 0,2 \\
\hline Assuntos internos da Câmara & 40 & 0,9 \\
\hline Economia & 1.180 & 26,3 \\
\hline Exército, Marinha, Armada & 262 & 5,8 \\
\hline Funcionários do Estado: assuntos individuais & 1.411 & 31,4 \\
\hline Funcionários do Estado: legislação, salários, equiparação de funções & 739 & 16,5 \\
\hline Habitação & 7 & 0,2 \\
\hline Imigração & 17 & 0,4 \\
\hline Infra-estrutura & 138 & 3,1 \\
\hline Legislação comercial, penal, civil & 127 & 2,8 \\
\hline Outros & 289 & 6,4 \\
\hline Política nacional & 137 & 3,1 \\
\hline Regulamentação de trabalho no setor privado & 7 & 0,2 \\
\hline Saúde e educação & 127 & 2,8 \\
\hline Sindicatos & 2 & 0,0 \\
\hline Total & $\mathbf{4 . 4 9 0}$ & $\mathbf{1 0 0 , 0}$ \\
\hline
\end{tabular}

Fonte: Câmara dos Deputados. Synopse dos trabalhos da Câmara dos Deputados. Rio de Janeiro: Imprensa Nacional, 1904 a 1914.

do Estado: legislação, salários, equiparação (num total de $16,5 \%)$, tratava-se da concessão de benefícios mais gerais (pagamentos, equiparação ou aumento de vencimentos e salários) para as diversas funções administrativas.

A predominância de assuntos relativos à administração pode ser explicada pelo domínio diário na administração da burocracia tanto militar quanto civil - característica do Estado moderno, e os discursos parlamentares mostram perfeitamente esta correspondência 
(Weber, 1984, p. 1.060). Entretanto, a atenção à montagem da burocracia do Estado brasileiro não parece ter gerado aquele tipo de Estado racional, tão acalentado por Weber, mas um tipo de Estado patrimonialista, como já teorizaram Faoro (1995) e Sérgio Buarque de Holanda (1993)

Além da atenção com o quadro administrativo e com a montagem da máquina administrativa no território nacional, os parlamentares discursavam para o mundo urbano. Eles referiam explicitamente a questão social e o trabalho (além da esfera do Estado) somente no âmbito da cidade. $\mathrm{O}$ mundo rural não fazia parte da pauta de discussão, ao menos no tema do trabalho.

Essa atenção ao urbano, não seria um paradoxo, uma vez que o Brasil e suas elites parlamentares ainda estavam primordialmente voltados para uma política econômica de defesa agroexportadora? Cabe assinalar que, nesse período, a produção do café se constituía no maior cômputo global da exportação. Entre os anos de 1900 e 1910, o café ocupava 51,3\% do total de exportações. Não seria de se esperar que os pronunciamentos estivessem voltados para a questão do trabalho e suas regras no campo, considerando, ainda, que o processo de urbanização era lento no Brasil, nesse período? Em 1920, de acordo com o IBGE (2003), 16\% da população vivia em cidades com mais de 20.000 habitantes, sendo que os dois principais centros urbanos eram Rio de Janeiro (790.000 habitantes) e São Paulo (579.000 habitantes).

A explicação para esse comportamento pode estar na herança cultural de séculos de domínio do latifúndio escravista e na duplicidade de papel da elite econômica, que assume compromissos com o capital agroexportador e com o incipiente capital industrial, na migração de capitais. Quando Sérgio Buarque de Holanda (1993) alerta para a ausência de uma racionalidade capitalista no Brasil, nas primeiras décadas do século XX, estava se referindo a essa "aventura" que o Brasil oligárquico e escravista fora até então. Essa cultura política 
de aversão à legislação trabalhista para o meio rural viria a se sustentar por mais de meio século, considerando-se que as primeiras regras de aposentadorias para trabalhadores no campo se deram nos anos 60 .

Essa relação do campo político com o espaço social mais amplo é possível ser percebida quando se compara a quantidade de projetos apresentados à Câmara de Deputados ao longo de dez anos, e reflete as conjunturas de crises políticas e econômicas enfrentadas pelo Brasil. Entre 1904 e 1914, a crise que antecede o pedido de moratória do Brasil, em 1913, e os períodos que antecedem as eleições presidenciais, há ligeiras ou acentuadas quedas no número de projetos, como se percebe no Gráfico 1.

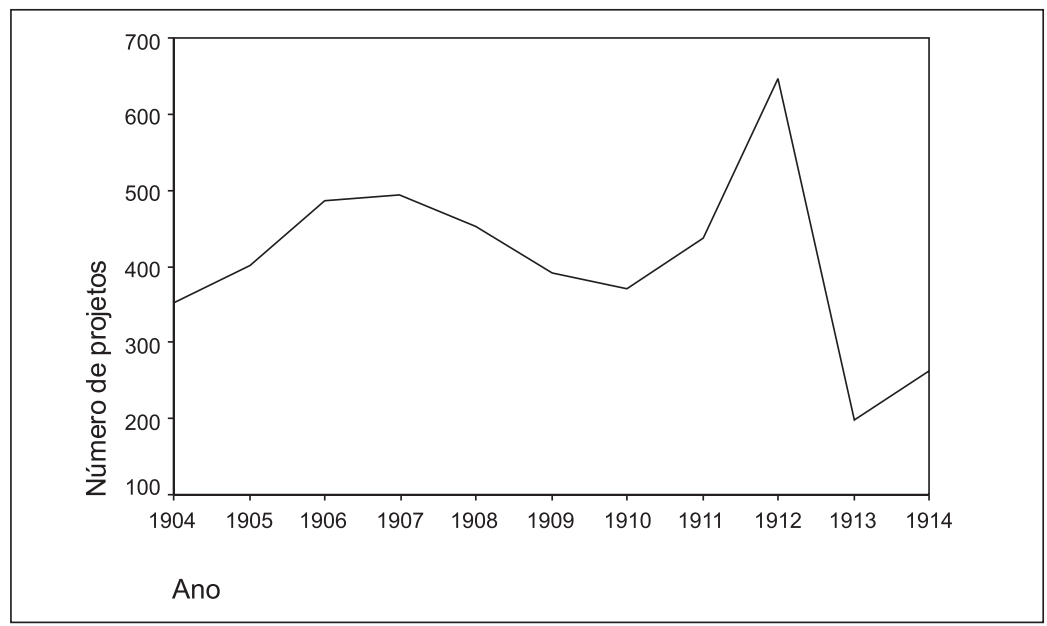

Gráfico 1 - Número de projetos apresentados à Câmara de Deputados - 1904-1912

Presume-se, de acordo com a categoria de campo político e espaço social de Bourdieu (1983), uma tensão e uma certa correspondência entre a dinâmica interna da política parlamentar e a estrutura social mais ampla. Havia uma clara diminuição de trabalhos parlamentares quando as lutas concorrenciais situadas fora dos limites parlamentares tornavam-se mais acirradas, como se percebe pelo gráfico. 
Mas quem eram estes deputados que discutiam a questão social como sendo uma questão do trabalho, do trabalhador do Estado? Representavam quais interesses? Quais proposições estavam presentes nessas discussões e nesses projetos?

As bancadas mais atuantes eram as do Distrito Federal, de Minas Gerais, de São Paulo e do Rio Grande do Sul, indicando que, em alguma medida, o processo de industrialização estava presente na agenda política. Cabe destacar duas importantes características do campo social, mais amplas e visíveis a partir da atuação das bancadas, uma de natureza econômica e outra política.

No campo econômico, a industrialização brasileira tem o seu início no Rio de Janeiro, sendo que São Paulo, rapidamente se transformaria no principal centro industrial (Carvalho, 1995, p. 44), justificando a maior presença das bancadas citadas nos discursos e apresentação dos projetos (sem entrar aqui na questão de número de representantes por Estado). No campo político, a configuração do sistema político brasileiro durante a República Velha era de fracionamento e regionalização partidária, de hegemonia entre as oligarquias paulista e mineira e o espectro da força política das oligarquias menores, como a gaúcha. $\mathrm{O}$ pacto oligárquico e a fragilidade dos partidos impunham uma dinâmica quase que pessoal e personalista ao jogo político.

Os deputados mais atuantes neste tema da questão social e do trabalho eram militares e bacharéis. A presença de bacharéis se justifica pela própria característica do período, pois a primeira fase da República já fora conhecida como República dos Bacharéis (Simoes, 1983). ${ }^{4}$ A presença de militares, porém, estava mais relacionada à cultura política do período, acentuada pela forte participação da caserna, inclusive na organização de oposição política ao regime e a situações de precariedade dos soldados e da sociedade em geral.

Dos deputados militares, Barbosa Lima e Figueiredo Rocha, ambos do Distrito Federal, destacaram-se pelas idéias e pela 
intensidade de seus pronunciamentos, sendo os que mais apresentaram projetos individualmente. Barbosa Lima foi responsável pelos discursos mais inflamados e favoráveis a restringir a questão do trabalho ao âmbito interno do Estado, influenciando as três legislaturas de que faz parte (de 1904 a 1912). Ele apresentou um total de 26 projetos. Já Figueiredo Rocha (assinou 33 projetos), juntamente com Rogério de Miranda (médico do Pará), e, além de apresentar projetos relacionados aos trabalhadores da Marinha e do Exército, foi responsável pelo primeiro projeto de jornada de 8 horas para todos os trabalhadores do país.

$\mathrm{Na}$ apresentação e defesa desses projetos para trabalhadores do Estado, havia pronunciamentos vinculados à idéia da questão social como voltada para regularizar as condições de trabalho, mas apenas para os vinculados ao Estado. Em linhas gerais, o parlamento deveria discutir e solucionar as condições precárias do trabalhador do Estado e não se envolver na esfera privada. O parlamento somente poderia voltar-se para o tema dos trabalhadores privados, na perspectiva destes parlamentares, quando os problemas dos trabalhadores e da administração do Estado estivessem solucionados. Prevaleceu, portanto, essa perspectiva etapista.

Os projetos de legislação social: predomínio de projetos para trabalhadores do Estado

Ao longo de dez anos, dentre os 25 projetos mais significativos listados no Quadro 1, percebe-se que as atenções estavam direcionadas para regularizar aposentadorias. Praticamente era apresentado um projeto por ano, sendo que, em 1912, houve um aumento considerável de projetos para aposentadorias, com seis no total. Outros projetos destinados a contemplar os trabalhadores do Estado estavam relacionados à preocupação de eliminar as distinções entre os diversos níveis e tipos de funcionários do Estado. 


\section{Quadro 1 - Projetos sobre o trabalho e funcionários do Estado - Brasil - 1904-1914}

\begin{tabular}{|c|c|c|c|c|}
\hline Autor & Bancada & Ano & $\mathrm{N}^{0}$ Projeto & Assunto \\
\hline Barbosa Lima & DF & 1904 & 104 & $\begin{array}{l}\text { Abolição da distinção entre empregados e } \\
\text { jornaleiros }\end{array}$ \\
\hline Leite Ribeiro & $\mathrm{DF}$ & 1905 & 310 & Fixa as férias dos funcionários públicos \\
\hline Figueiredo Rocha & DF & 1906 & 166 & $\begin{array}{l}\text { Uniformização das horas de trabalho e } \\
\text { vencimentos dos operários da União }\end{array}$ \\
\hline Graccho Cardoso & $\mathrm{CE}$ & 1906 & 197 & Aposentadorias dos funcionários públicos \\
\hline Lobo Jurumenha & RJ & 1906 & 299 & $\begin{array}{l}\text { Revisão do quadro dos funcionários aposentados } \\
\text { e das pensões }\end{array}$ \\
\hline Justiniano de Serpa & PA & 1907 & 259 & Aposentadoria dos funcionários públicos \\
\hline Comissão de redação & Vários & 1908 & 6 & Contagem de tempo aos diaristas \\
\hline Justiniano de Serpa & $\mathrm{PA}$ & 1908 & 166 & Regula a concessão de aposentadoria \\
\hline $\begin{array}{l}\text { Comissão } \\
\text { constituição, } \\
\text { legislação e justiça. }\end{array}$ & Vários & 1909 & 166 & $\begin{array}{l}\text { Uniformiza as horas de trabalho e os } \\
\text { vencimentos de diversas classes de operários das } \\
\text { oficinas da União }\end{array}$ \\
\hline Gracho Cardoso & $\mathrm{CE}$ & 1909 & 167 & $\begin{array}{l}\text { Equipara vencimentos de funcionários das } \\
\text { secretarias de Estado }\end{array}$ \\
\hline Comissão de finanças & Vários & 1909 & 223 & $\begin{array}{l}\text { Manda governo organizar relação de operários e } \\
\text { jornaleiros das oficinas da União }\end{array}$ \\
\hline Lindolpho Camara & $\mathrm{RN}$ & 1911 & 91 & Aposentadoria dos funcionários públicos \\
\hline Lindolpho Camara & RN & 1912 & 103 & Aposentadoria de empregados públicos \\
\hline Senado & Vários & 1912 & 165 & Aposentadoria dos funcionários \\
\hline Arlindo Leoni & $\mathrm{BH}$ & 1912 & 368 & $\begin{array}{l}\text { Aposentadoria e montepio dos membros do } \\
\text { ministério público federal e do Acre }\end{array}$ \\
\hline Pereira Nunes & RJ & 1912 & $103 \mathrm{C}$ & $\begin{array}{l}\text { Aposentadoria dos funcionários das Caixas } \\
\text { Econômicas }\end{array}$ \\
\hline José Bonifácio & MG & 1912 & $103 \mathrm{D}$ & $\begin{array}{l}\text { Aposentadoria de empregados públicos e } \\
\text { contagem de tempo estadual e municipal }\end{array}$ \\
\hline Não consta autor & $\begin{array}{c}\text { Sem } \\
\text { informação }\end{array}$ & 1912 & $103 \mathrm{E}$ & $\begin{array}{l}\text { Aposentadoria de empregados públicos e } \\
\text { contagem de tempo estadual e municipal }\end{array}$ \\
\hline Comissão de redação & Vários & 1913 & 18 & Estende favores aos funcionários públicos civis \\
\hline Moniz Sodré & $\mathrm{BH}$ & 1913 & 153 & Organiza o estatuto do funcionário público \\
\hline Lindolpho Camara & $\mathrm{RN}$ & 1913 & 192 & Aposentadoria dos funcionários públicos civis \\
\hline Comissão de finanças & Vários & 1914 & 18 & Autoriza revisão de aposentadoria \\
\hline Comissão de finanças & Vários & 1914 & 36 & Hora de trabalho nas repartições federais \\
\hline Camillo de Hollanda & PB & 1914 & 212 & $\begin{array}{l}\text { Estabelece condições do funcionalismo público } \\
\text { civil e militar }\end{array}$ \\
\hline Correa de Freitas & PR & 1914 & 247 & Cria um seguro de pensão a velhice \\
\hline
\end{tabular}

Fonte: Câmara de Deputados. Synopse dos trabalhos da Câmara dos Deputados. Rio de Janeiro: Imprensa Nacional, 1904 a 1914. 
Nos discursos das elites parlamentares brasileiras que discutiram os assuntos dos trabalhadores do Estado, é possível encontrar as suas visões sobre o caráter mais geral do trabalho. Para o deputado mineiro João Pandiá Calógeras, conhecido pela sua intervenção em assuntos econômicos, os projetos destinados ao funcionalismo público continham um part pri, pois "o que é certo é o que se criar será uma situação privilegiada para operários do Estado" (Dep. Calógeras, 1912, p. 582).

Essas elites parlamentares se referiam à variedade de tipos e formas de ligação dos trabalhadores com o Estado, em função de não existir um plano geral do funcionalismo público. Eram os trabalhadores jornaleiros - que recebiam do Estado por dia trabalhado -, eram os operários contratados para obras com tempo determinado - para construir estradas, por exemplo -, eram os funcionários de escritórios - identificados pelos parlamentares como sendo os de serviço mais qualificado - entre outros. Quanto a esses trabalhadores, aos olhos desta elite parlamentar, era preciso minorar seus sofrimentos em termos de jornada de trabalho, salário e aposentadorias.

Com relação aos projetos sobre o trabalho e os trabalhadores do setor privado, houve um total de sete projetos (Quadro 2).

\section{Quadro 2 - Projetos de legislação do trabalho nos setores privados - Brasil - 1904 a 1914}

\begin{tabular}{|l|c|c|c|l|}
\hline \multicolumn{1}{|c|}{ Assunto } & N $^{\circ}$ Projeto & Bancada & Ano & \multicolumn{1}{|c|}{ Autor } \\
\hline Acidentes e indenização a operários & 169 & PE & 1904 & Medeiros e Albuquerque \\
\hline Descanso dominical obrigatório & 129 & PA & 1907 & Passos Miranda Filho \\
\hline Indenização de acidente de trabalho & 273 & CE & 1908 & Graccho Cardoso \\
\hline Indenização de acidente de trabalho & 337 & RS & 1908 & Wenceslau Escobar \\
\hline $\begin{array}{l}\text { Fixa em 12 h tempo de trabalho de } \\
\text { empregados do comércio }\end{array}$ & 79 & DF & 1911 & Nicanor Nascimento \\
\hline $\begin{array}{l}\text { Estabelece o máximo do trabalho } \\
\text { para os operários de 8 h, determina } \\
\text { as condições do salário, e dá outras } \\
\text { providências }\end{array}$ & 4 & DF & 1912 & $\begin{array}{l}\text { Figueiredo Rocha e } \\
\text { Rogério de Miranda }\end{array}$ \\
\hline Contrato entre patrão e operário & 243 & PR & 1914 & Correa de Freitas \\
\hline
\end{tabular}

Fonte: Câmara de Deputados. Synopse dos trabalhos da Câmara dos Deputados. Rio de Janeiro: Imprensa Nacional, 1904 a 1914. 
$\mathrm{Na}$ apresentação de projetos para todos os trabalhadores privados abre-se espaços para questionamentos sobre diferenciações sociais, mesmo que pela via da negação dessa diferenciação social. Dialeticamente, apareceram discursos que reforçavam precisamente os níveis diferenciados de direitos relacionados aos diferentes tipos de trabalhadores, como se observa na passagem a seguir:

Desde sempre, mesmo sob o mais íntimo influxo do regime extinto, a tendência característica de nossa sociedade foi para a mais ampla igualdade de condições jurídicas de todos os seus membros. [...] Nunca prevaleceu em nosso país, distinção de classe. Sempre vivemos, quaisquer que sejam as diferenças de fortuna, de inteligência de saber, de posição, num amalgama geral e completo. Confundimonos todos, nas relações comuns da vida, constituindo, uma verdadeira e ampla democracia. Somos, neste sentido, uma sociedade homogênea. [grifos meus] (Parecer da Comissão de Constituição e Justiça, 1909, p. 473)

Mesmo que esses deputados concebessem a diferenciação entre sujeitos, tais discursos de não-diferenciação podem representar uma forma de não tocar em um ponto crucial do sistema, isto é, no conjunto das diferenças e desigualdades sociais vigentes no país. Essas elites parlamentares poderiam estar influenciadas pela dicotomia entre trabalho escravo e trabalho livre, como salientamos logo no início deste artigo. Há, claramente, resistência a consolidar o uso da mão-de-obra livre com base em uma legislação, como já se evidenciava em países vizinhos como Uruguai, Argentina e Chile. Em termos da nossa realidade, neste caso, o inusitado parece ser a presença dos discursos que apontavam para o outro sujeito do campo dos trabalhadores, o sujeito da esfera privada.

Em linhas gerais, portanto, podem-se identificar pelos menos duas correntes de discursos que se manifestavam sobre o trabalho e as possibilidades de construir soluções para esse tema ao longo desses dez anos. São elas:

I - a idéia de legislação por etapas com prioridade para a esfera pública e com um discurso questionador sobre a existência de operários no país; 
II- a necessidade de atingir a questão social pela atenção a todos os trabalhadores e não somente aos ligados ao Estado. Esta corrente apresenta, ainda, um discurso trabalhista e genérico, antecedendo aquele que vai ser elaborado nos anos 20 .

O discurso da legislação social por etapas e do mito sobre a existência do operário

Entre os parlamentares, a característica marcante das discussões sobre o trabalho foi a noção de etapa. Primeiramente, deveria-se tratar dos assuntos do trabalho no Estado e, posteriormente, no âmbito privado.

Dos 42 deputados que se pronunciaram sobre o trabalho como uma questão social, quinze deles o fizeram explicitamente pela idéia das etapas. Podem ser destacados os deputados Barbosa Lima, Alcindo Guanabara, Monteiro Lopes, Irineu Machado, Honório Gurgel, Heredia de Sá - da bancada do Distrito Federal; o deputado paulista Galeão Carvalhal; o deputado pelo Estado do Ceará, Graccho Cardoso (este apresenta, apesar disso, um projeto de acidente de trabalho para os operários em geral); o gaúcho Homero Baptista; o deputado Costa Pinto, da Bahia; o mineiro Josino de Araújo; Paula Ramos, de Santa Catarina; e Paulino de Souza, do Rio de Janeiro. Os demais que se pronunciam sobre o tema não explicitam essa noção de etapas, embora discutam a necessidade e defendam a legislação para os funcionários do Estado.

Nos discursos há a recorrência de que "o primeiro passo vai (seria) ser dado, com a adoção de medidas de equiparação dos operários aos funcionários da União, e isso demonstra nosso interesse pela sorte do proletariado" (Dep. Galeão Carvalhal, 1909, p. 487). Este mesmo deputado assegura que esses projetos "não permitiriam que o operário da União, ou melhor, o proletariado fosse oprimido, vivendo em sofrimentos penosos, sem instrução e sem cultura moral". 5 
O discurso genérico da premência dos projetos para os trabalhadores do Estado estava ancorado em uma interpretação gradativa da realidade. Ao considerar as dificuldades econômicas do país e os trabalhadores como os que mais sofriam as consequiências destas dificuldades, as elites parlamentares, em geral, asseveravam que os funcionários e operários do Estado sofriam mais do que os outros. Elas forjavam um discurso pautado pela diferenciação de sofrimentos e pelo conseqüente merecimento, e pela melhoria das condições dos operários do Estado, como assinalou um deputado paulista, reconhecidamente opositor da legislação social, deputado João Luiz Alves (Dep. Galeão Carvalhal, 1909, p. 487).

Apesar dos conflitos entre as bancadas, um ponto de consenso parece claro: não se tratava, ainda, de legislar para todos. Quando perguntado sobre ampliar a legislação para os trabalhadores do setor privado, Irineu Machado (1912, p. 486), o representante da bancada do Distrito Federal respondeu categoricamente que este era outro assunto. ${ }^{6}$ As motivações desses projetos e discursos sobre formas de melhorar a vida dos trabalhadores ligados ao Estado se confundem, em alguns casos, com o discurso de eficiência administrativa. Foi nesta direção que o Projeto de n ${ }^{\circ} 223$, de 1909, previu a incorporação dos operários ao Estado após o tempo de cinco anos de serviço, demandando uma investigação sobre a quantidade de funcionários existente no Estado. ${ }^{7}$

Nos projetos e nos discursos, foi usada, igualmente, uma justificativa ideológica para não efetivar uma legislação social para todos os trabalhadores. O deputado do Distrito Federal Monteiro Lopes assegura que, de todas as nações civilizadas, somente falta ao Brasil legislar para o trabalho. Para ele não havia um Ministério do Trabalho porque era preciso evitar que o país fosse chamado de socialista. Pelos pronunciamentos deste e de outros deputados, portanto, vê-se a formulação de uma justificativa ideológica para não viabilizar uma legislação social: o escopo das posições socialistas (Dep. Monteiro Lopes, 1910, p. 290). 
O mito da debilidade da classe operária e necessidade da ordem: um revela a contradição do outro

Foi recorrente entre os deputados que se manifestaram sobre o tema do trabalho o discurso da ausência de uma movimentação operária no Brasil como a verificada na Europa. Com frases contundentes como "aqui não tem miséria" (Parecer da Comissão de Constituição e Justiça, 1912) e "o problema operário ainda é um mito" (Dep. Antonio Carlos, 1911, p. 1.004), os deputados discutiam a primazia de aposentadoria para o funcionalismo público, em detrimento de ampliá-la para outros setores.

Esse discurso se mostrava mais intensamente entre os deputados que defendiam a idéia de uma legislação para os operários pertencentes ao Estado do que entre os deputados da corrente "trabalhista". É relevante frisar que, mesmo nos discursos proferidos por esses deputados favoráveis à legislação social para todos, havia incidência da noção de que, no País, o movimento operário ainda não adquirira as mesmas proporções logradas entre os europeus.

Na maioria dos discursos, a afirmação de que ainda não existia uma classe operária brasileira estava associada à comparação com países europeus, sobretudo ao exemplo da Alemanha e às medidas implementadas por Bismarck. Os defensores dessa noção - no Brasil não havia um movimento operário ou uma classe operária que pudesse ameaçar a ordem - argumentavam que as manifestações operárias presentes na capital carioca e paulista não representavam o país: "No Brasil, que o Rio de Janeiro desconhece, o problema operário é ainda um mito!" (Dep. Antonio Carlos, 1911, p. 1.004).

Ao usar o sentido de mito operário, em alguma medida, indicam os deputados ter conhecimento sobre a movimentação operária em alguns Estados. Eles faziam alusões aos movimentos grevistas dos trabalhadores do porto de Santos, ao movimento grevista de trabalhadores de fábricas têxteis na capital paulista, ou, ainda, à preparação do quarto Congresso Operário em dezembro de 1912. 
Haveria um paradoxo no pensamento dessas elites parlamentares brasileiras, uma vez que explicitavam o problema operário no Estado e o negavam para os trabalhadores do setor privado? A aparência da negação se dissolve pela palavra desses mesmos deputados, que se mostravam atentos à questão da ordem. Deputados da corrente das etapas e deputados da corrente trabalhista inseriam nos seus discursos o que já se verificava na advertência do deputado Gurgel: evitar a desordem. Disse o deputado que "nossa terra ainda não é, felizmente, agitada como os países do velho mundo, forte e constantemente, pelas tremendas imposições da chamada questão social, que no sentir (...)" (Dep. Homero Baptista, 1909, p. 478).

Mesmo entre os deputados ligados à corrente dos que defendiam uma legislação social para todos, aparecia essa noção de que no Brasil a situação era diferente da Europa, como se percebe no pronunciamento do deputado paulista Martim Francisco, ao dizer que:

Pertence ao número dos que acham evitável, no Brasil, a questão social que se agita na Europa; aqui todos são operários, e a igualdade adquirida no meio nacional facilitará inegavelmente o desdobramento pacífico do grande problema. Bastará para isso que as aspirações operárias entrem no que é praticamente possível à autoridade pública se resolva a não sair da lei. (Dep. Martim Francisco, 1914, p. 559) [grifo meu]

A idéia de que no Brasil não havia as mesmas condições miseráveis e difíceis vigentes na Europa era recorrente entre todos os deputados. Na visão destas elites parlamentares brasileiras, o país ainda estava muito longe da realidade que se apresentava na Europa. Nos seus discursos, é possível perceber, num certo sentido, um desejo de fazer valer no Brasil apenas a parte boa do progresso europeu. Esta idéia, aliás, ocorreu igualmente entre as elites parlamentares uruguaias, com uma diferença.

Portanto, no Brasil a discussão foi diferente daquela que ocorria no continente europeu. Como afirma Rosanvallon (1998), no caso europeu, por conta desta discussão, forjou-se o paradigma da 
solidariedade ou da responsabilidade, que redundaria em diferentes projetos assumidos por governos ingleses, franceses, alemães, principalmente. Para esse autor, a introdução do seguro na gestão do social se impôs progressivamente porque ela permitia abandonar os paradoxos decorrentes de uma visão puramente individualista da sociedade. É um dos elementos que evidencia a passagem para o Estado-providência, cujos princípios estão alicerçados na idéia de substituir a incerteza da providência religiosa pela certeza da providência estatal, em substituir a incerteza da providência religiosa pela certeza e a regularidade da providência do Estado leigo.

Cabe salientar que o contexto no qual estes pronunciamentos se mostram mais recorrentes é o de um ambiente de movimentações operárias, surgimento de sindicatos, congressos operários e algumas greves importantes em São Paulo, por exemplo. Se esses movimentos não podem ser compreendidos como amorfos, embora em muitos casos tivessem vida efêmera, em geral o movimento operário somente teria maior repercussão com a primeira greve geral de 1917.

No biênio 1912-13, houve demonstrações de intensa vitalidade do movimento operário: realização de dois congressos operários, a resistência à lei de expulsão dos trabalhadores estrangeiros, os comícios contra a carestia no Rio, um deles contando com 10 mil pessoas (em 16 de março, no Largo de São Francisco), 23 greves em São Paulo, sendo que uma estendida a quatorze estabelecimentos industriais (Relatório..., 1913). No entanto, se forem tomadas as greves como indicadores exclusivos, nos três anos seguintes e os anteriores a 1912, houve um cenário de refluxo, sendo que as movimentações operárias comparativamente mais intensas se desencadearam após 1917 (Carone, 1989; Vianna, 1976; Gomes, 2002; Fausto, 2000).

Diante das pressões sociais materializadas em movimentos grevistas ou em iniciativas de organizações sindicais ainda incipientes, esses parlamentares inicialmente encaminhavam a discussão na direção da criminalização desses movimentos e não reconheciam os operários como sujeitos políticos. A partir de 1908, notam-se, nos discursos e nos projetos, ações para contornar o avanço dessas 
pressões, principalmente aquelas originadas na atuação de imigrantes mais politizados. Aumenta a preocupação desses imigrantes, que eram incorporados na incipiente industrialização do país e traziam consigo as experiências de lutas nos países de origem (Carone, 1989).

A confrontação entre diferentes interesses sociais estava explicitada nos debates entre as elites parlamentares. Estas confrontações que derivavam das pressões operárias indicam um cenário em aberto, isto porque as elites parlamentares apostavam em controles sistemáticos, seja pela via da força, do uso policial (em muitas discussões, elas apoiavam essas iniciativas) ou da coibição pela via legal, quando elas apresentavam projetos neste sentido.

\section{Os projetos de jornada de trabalho no Brasil}

Foram apresentados à Câmara dos Deputados sete projetos de legislação do trabalho para todos os operários do Brasil entre os anos de 1904 e 1914. A importância desses projetos, mormente tenham sido arquivados, está na imposição do tema e na obrigatoriedade do parlamento se pronunciar oficialmente sobre o tema do trabalho, até então negada. Destes sete projetos, dois merecem especial atenção (limitação da jornada de trabalho para os comerciantes em 12 horas e jornada de 8 horas), pois apresentam elementos explícitos sobre a questão social como sendo uma questão do trabalho, na ótica dos deputados proponentes.

O projeto de limitação de jornada de trabalho em 12 horas para trabalhadores do comércio continha, entre os artigos, além da quantidade de horas, outros assuntos como trabalho exercido por crianças e mulheres, repouso semanal, pagamentos de feriados e domingos, acidentes de trabalho. Esta era uma característica desse projeto que aparecia igualmente no projeto de jornada de 8 horas de trabalho, com inclusão do tema de salários (Anais da Câmara de Deputados do Brasil, dia 15 de julho de 1911, p. 170-176). Com relação à contratação de crianças, o artigo 4 previa que: 
- não poderiam ser contratados para empregados do comércio menores de dez anos de qualquer sexo;

- só poderiam ser tomados como empregados no comércio menores de quinze anos e maiores de dez anos, quando soubessem ler e escrever em português;

- os menores de quinze anos não poderiam ser obrigados a trabalhar por mais de 8 horas diárias, incluindo uma para a refeição e repouso;

- não poderiam ser contratados para trabalhar em estabelecimentos comerciais à noite os menores de dezoito anos e as mulheres;

- nos aposentos onde trabalhassem as mulheres, haveria tantos bancos ou cadeiras quantas as empregadas.

O projeto mais significativo é o que previa oito horas de jornada de trabalho. Esse projeto de lei de jornada de 8 horas dos deputados Figueiredo Rocha e Rogério de Miranda era parcimonioso, pois continha apenas seis artigos relacionados ao tempo de trabalho e às indenizações por acidente de trabalho. Nestes artigos estava disposto integralmente que:

Art 1 - O trabalho do operariado em geral fica reduzido ao máximo de oito horas diárias.

Art 2 - Ficam expressamente proibidos os serões em todas as fábricas e oficinas.

Art 3 - O operariado que contar com mais de cinco anos de serviço na casa perceberá dois terços da diária que tinha a qual será paga pelo seu patrão, companhia, empresa, associação, etc. quando inutilizado em seus serviços.

Art 4 - A infração da presente lei será punida com a pena de prisão de três a seis meses.

Art 5 - O governo expedirá regulamentos necessários para a fiscalização e execução da presente lei, que será posta em execução logo após a sanção.

Art 6 - Revogam-se as disposições em contrário. ${ }^{8}$ 
Nesses poucos artigos do projeto de lei, estão configurados os temas sensíveis para as elites parlamentares brasileiras, pois previam não só a participação do Estado nas relações privadas entre trabalhadores e empregadores, mas também a criação de condições para que fosse cumprida a lei. Isso indicava uma outra contenda não colocada explicitamente, mas permeável em toda e qualquer discussão: a aplicação da lei em nível nacional. Em outras palavras, uma das argumentações usadas para bloquear a tramitação destes projetos para todos os trabalhadores do país eram os diferentes interesses regionais. Não era possível legislar a matéria pela característica diferenciada dos Estados, discursavam os deputados. O arquivamento do projeto é uma variável forte para sustentar, sem prejuízo de equívocos, que o sentido predominante no Parlamento era negar para os trabalhadores do setor privado uma legislação social.

O Estado é um dos protagonistas do debate sobre implementação das regras de trabalho no setor privado. Em defesa do seu projeto de 12 horas para os comerciantes, o deputado Nicanor Nascimento disserta sobre as condições do mercado de oferta de trabalhadores:

[...] por quanto se há grande oferta de trabalhadores e pequena oferta de lugares, a consequiência é que o trabalhador que oferece o seu trabalho, o seu serviço, oferece-o em condições muito inferiores àquele que recebe uma proposta de muitíssimos indivíduos necessitados de trabalho e de subsistência. Essa inferioridade que se estabelece para o contratante deve ser amparada pelo Estado no interesse do próprio Estado, na manutenção das qualidades superiores da raça, do desenvolvimento da inteligência, da vontade, enfim daqueles espíritos juvenis que se tem de desenvolver no país. (Dep. Nicanor Nascimento, 1911, p. 171)

Nessa passagem, aparece um outro elemento comum à justificativa do projeto de 8 horas, elaborada por Figueiredo Rocha. Trata-se da observação de que a limitação da jornada de trabalho reforçaria as condições de saúde e sobrevivência, em última instância, do trabalhador. Em alguma medida, mesmo que não tenham relações 
com as idéia marxistas, aparece a perspectiva, já apontada por Marx, de que os patrões percebem que a exploração do trabalhador poderia levá-lo à morte, dado o esgotamento físico a que poderia levar a exploração, não só em número excessivo de horas de trabalho, como nas condições materiais do local de trabalho.

Para os deputados responsáveis pelo projeto de 8 horas, o eixo central era a idéia de proporcionar condições de sobrevivência ao operário, apesar de serem mencionados a necessidade da intervenção do Estado nas relações contratuais entre operários e patrões e o aumento de oferta de emprego, dada a redução de número de horas, possibilitando ganhos produtivos. Em seis dos sete parágrafos que integram a justificativa do projeto de 8 horas, havia a recorrência ao tema da sobrevivência do operário, explicitada nas diversas formas usadas para indicar essa preocupação (Dep. Nicanor Nascimento, 1911, p. 171). O tempo era considerado por eles como um elemento importante (ou precioso, como é citado na mesma justificativa) para o operário, no que diz respeito à existência propriamente física. ${ }^{9}$

Contrastando, por fim, as motivações apresentadas nos dois projetos, pode-se afirmar que, em relação à proposta de 8 horas para a jornada de trabalho, não havia menção sobre regular trabalho para mulher e crianças, nem sobre a lei se constituir em algum direito, e não aparece a noção de essa regulamentação se constituir em forma de controle da ordem ou mesmo evitar a desordem.

\section{A oposição à limitação de jornada de trabalho}

A oposição ao projeto de jornada de trabalho limitado em 8 horas é selada com o parecer da Comissão de Constituição e Justiça. O parlamento brasileiro, pela primeira vez na República, se pronunciou formalmente quanto ao tema.

Tendo em vista os exemplos de várias iniciativas ocorridas na França, na Suíça, mas especialmente na legislação alemã, o parecer sobre o projeto de 8 horas de jornada afirmava que, “[...] não pode 
ser posta em dúvida a constitucionalidade do projeto de número 4 , do corrente ano [...]". Isto significava um progresso em relação ao entendimento vigente desde a Constituinte republicana de 1891. Porém, se no mérito a matéria foi julgada pertinente à Câmara de Deputados, ela foi rejeitada em termos de efetividade prática.

Os debates entre os deputados que compuseram a Comissão responsável pela análise do projeto de 8 horas não foram registrados. Foram registrados apenas os pronunciamentos finais dos integrantes da comissão, da mesma maneira como foi registrada apenas uma manifestação da sociedade favorável ao projeto, através de um telegrama dos "amigos operários do estado da Bahia" que pediam que este projeto, como ato humanitário, fosse aprovado pelo legislativo, conforme telegrama enviado à Comissão de Constituição e Justiça da Câmara de Deputados no dia 11 de junho de 1912. Também não foram registrados nenhum tipo de manifestação de inconformidade ou oposição por parte dos empregadores, o que pode significar, talvez, que o projeto adquirira pouco destaque naqueles meses.

"No Brasil a indústria não existe!" Com esta afirmação categórica, feita a ressalva da ocorrência da indústria apenas em algumas cidades, foi colocado um dos eixos de oposição à legislação social, ou à jornada de 8 horas. Em longas citações sobre outros países e seus progressos industriais, o Brasil era descrito como um país que no máximo possuía uma lenta marcha na direção da industrialização (Parecer da Comissão de Constituição e Justiça, 1912, p. 167-169). No país não haveria indústria como no continente europeu, não haveria pobreza, percepção já esboçada pelo menos mais de uma vez na Câmara de Deputados. A não existência de miséria ou mesmo de uma quantidade de operários era uma idéia usada igualmente para a não necessidade da legislação operária ou para justificar a situação vigente. ${ }^{10}$

Com relação à jornada de trabalho, os temas relativos à limitação da jornada noturna, do trabalho de mulheres e crianças eram situados 
como justos, mas contraditórios com as liberdades individuais. Fizeram o discurso das liberdades individuais os deputados Porto Sobrinho, Carlos Maximiliano (embora propusesse limitação para o trabalho de menores de doze anos), Henrique Valga, Gumercindo Ribas, Cunha Machado e Afrânio Mello.

Esses deputados contrários ao projeto pouco usaram da noção de perigo das classes laboriosas no Brasil. Os deputados que mais apelaram a esse argumento parecem ter sido justamente aqueles favoráveis a uma legislação social. Seria uma espécie de moeda social? Parece recorrente nos discursos da oposição ao projeto a certeza sobre a possibilidade de que, no Brasil, as pressões sociais ainda pudessem ser contornadas. O projeto de 8 horas foi importante por forçar o pronunciamento, na forma de um parecer. Mesmo que não tenha prosseguido na tramitação normal da Câmara, este parecer indica um tour de force na direção dessa temática.

\section{Considerações finais}

Em síntese, com relação ao Brasil, houve a recorrência do discurso sobre o trabalho e sobre uma legislação social e urbana. Em outras palavras, um dos resultados empíricos foi a confirmação de que as elites parlamentares brasileiras discutiam o tema do trabalho como uma questão social nos primeiros anos do século XX, e não somente a partir de 1917, como a literatura tem frisado.

No conjunto dos deputados que se pronunciaram explicitamente sobre o tema, nesta medida, formaram-se duas correntes distintas quanto à forma de tratá-lo. A primeira corrente de deputados, predominante na Câmara, era aquela que congregava os deputados defensores de uma legislação social no âmbito do Estado, em termos de jornada de trabalho, equiparação entre funcionários e operários da União e aposentadoria. A segunda corrente de deputados, em larga desvantagem numérica, apresentou à Câmara projetos que atingiam a todos os operários do país e, ainda que seus integrantes não fossem contrários às regras para os operários do Estado, realizavam um discurso da Ordem e do Estado. 
Um outro aspecto visível nos discursos, prioritariamente dos deputados que defendiam a visão em etapas, primeiro para o Estado, é a tentativa de negar a existência de grandes diferenças na população brasileira, reforçada pelo argumento de que não havia no Brasil uma situação operária como a européia. Havia um conteúdo progressista e conservador ao mesmo tempo: o progresso econômico só poderia ser obtido se fosse mantida uma determinada ordem, na qual os homens ocupassem papéis definidos e da qual tivesse sido extirpado o conflito.

Percorrendo os discursos sobre a legislação para os funcionários do Estado foi possível encontrar visões dos parlamentares sobre a questão social, sobre o trabalho em geral. Na polêmica sobre a regulamentação do trabalho para os operários, jornaleiros e funcionários do Estado, essas elites parlamentares usavam o recurso do contraste com a situação dos "outros" operários que integravam o mundo do trabalho da indústria emergente e do comércio em geral. Nos discursos encontram-se explicitadas suas visões sobre a relação social, a idéia de sociedade brasileira, as funções do Estado e, por fim, como o trabalho era percebido por elas, como uma questão social.

Por fim se teve, nestes anos, possivelmente a primeira manifestação na Câmara Federal brasileira do que posteriormente seria elaborado como a ideologia da outorga: seria o Estado que, providencialmente, concederia ao operariado a legislação social, minimizando o potencial de pressão e da prática efetiva dos trabalhadores urbanos na luta por seus direitos. Isto porque parece ter havido entre essas elites parlamentares uma supervalorização do papel do Estado, mesmo que a idéia de menos Estado nas relações privadas de trabalho tenha sido vencedora.

Em síntese, as análises dos discursos parlamentares sobre a questão social como um assunto relativo ao trabalho demonstrou que os embates entre as diferentes visões parlamentares estavam conectados com o mundo social - ainda que este mundo (como o caso do meio rural) estivesse ausente das recorrências explícitas nos discursos. No horizonte destes embates, estava a interrogação sobre como equacionar melhor as diferenças entre os agentes sociais, 
embora, no caso brasileiro, essa assertiva tenha sido construída de maneira invertida. Nos discursos das elites parlamentares brasileiras, de um modo geral, a concepção recorrente foi a omissão das grandes desigualdades existentes no Brasil.

Havia uma heterogeneidade de pensamento dessas elites parlamentares. As votações dos projetos pertinentes aos temas vinculados como uma questão social indicaram, porém, o predomínio de uma idéia sobre as demais. Predominou a perspectiva de que, se havia uma questão social, principalmente no sentido de dificuldades materiais, inicialmente deveriam ser atendidos os que estavam mais diretamente ligados ao Estado, ou seja, os funcionários do Estado.

Essa centralidade no Estado foi concebida pelas elites parlamentares brasileiras como uma posição estratégica para o crescimento do Estado republicano brasileiro através da expansão da burocracia, do aumento de sua capacidade fiscal e do próprio aumento das forças militares. O número de projetos encaminhados na Câmara Federal assegura a validade dessa proposição. Foi possível constatar uma concentração de projetos relativos à administração do Estado, sendo que estes, na sua maioria, beneficiariam indivíduos. Como afirma Elisa Reis (1985), numa perspectiva de localizar os interesses presentes neste processo de construção do Estado republicano, os interesses agroexportadores dominantes do período, ao politizarem a economia, confeririam ao Estado uma posição estratégica. Cabe ressaltar que Wanderley Guilherme dos Santos (1987) afirma que, até os anos 50, os partidos tiveram pouca relevância na construção da identidade política e coletiva do Brasil. Esta tarefa foi cumprida pelo Estado, pela burocracia, pelas forças armadas e pela inteligência.

Ao se afirmar que o campo do Legislativo é um campo de dominação, no entanto, não se está atribuindo um status negativo à política, no sentido que lhe atribuiu Marx ao analisar as limitações políticas das reformas na Alemanha, por exemplo. Para ele, havia uma contradição irreconciliável entre o político e o social, dado o caráter antagônico da base social perpetuada pela própria estrutura política. 
Como afirma Bourdieu (2000), a cultura dominante e a fixação de um consenso a seu respeito não impede que se produzam alternativas, podem-se atribuir ao campo da política possibilidades de alternativas como produto de lutas entre diferentes concepções. As condições de lutas não estavam totalmente encerradas, ainda que a participação política fosse restritiva, e o campo da política oficial fosse dominado pelas elites parlamentares econômicas e culturais da época, deixando de fora outros grupos sociais, como os próprios trabalhadores.

Havia diferenças mesmo entre essas elites, e essas diferenças poderiam resultar em desfechos diversos. Mesmo em ambiente de aparente ausência de grupos como os trabalhadores, estes estavam presentes na cena política. Os pronunciamentos e discursos de deputados brasileiros, como Nicanor Nascimento, por exemplo, ao apresentar um projeto de lei de jornada de 8 horas, no entanto, remetem às possibilidades de alternativas, mesmo que numa perspectiva nãorevolucionária, como pensava Marx ao formular seu conceito de política negativa.

\section{Notas}

1 Os comentários recebidos sobre o presente artigo foram bastante úteis, em especial aqueles sobre as diversas escolas de pensamento sobre a questão social.

2 Este artigo é resultado de pesquisas realizadas para a elaboração da tese de doutorado intitulada "Elites parlamentares e a questão social no Brasil e no Uruguai: 1904-1914", tese orientada pela professora Fernanda Sobral, do Departamento de Sociologia da UnB, e defendida em dezembro de 2004.

3 Para maior detalhamento, ver o Quadro 8 - Sessões legislativas e os discursos com referência ao tema do trabalho - Brasil - 1904-1914, em Ranincheski (2004).

4 Este quadro é alterado ao longo do século XX. Em pesquisa realizada sobre o perfil dos senadores da República na década de 1990, foi constatado o declínio desta carreira, pois o número de bacharéis chegou 
a apenas $37 \%$ do total de senadores, seguida de profissões tradicionais como a medicina $(8 \%)$ e engenharia $(11 \%)$. Ver Ranincheski e Lemos (2001). Este declínio de bacharéis é confirmado pela pesquisa do cientista Fabiano dos Santos (2000).

5 Ver também os discursos do deputado Barbosa Lima (30 jun. 1908, p. 627) e a sua defesa de medidas para os trabalhadores do Estado. Para o deputado Graccho Cardoso (22 set. 1909, p. 428), "são freqüentíssimos os casos, entre nós, de empregados públicos que, na impossibilidade absoluta de viverem dos próprios vencimentos vão buscar outros trabalhos e isso é inadmissível".

6 Irineu Machado (28 out. 1911, p. 271) defendia também que: “(...) se esses funcionários (do Estado) podem viver com tais insignificantes vencimentos, inferiores até aos muitos operários e trabalhadores das classes ínfimas".

7 Interessante destacar que esta investigação previa um mapeamento, baseado em um questionário aplicado às repartições públicas da União, do quadro administrativo do Estado. As perguntas, em um total de nove, eram as seguintes: Quantos são os operários do quadro desta repartição? Quantos são os operários fora do quadro desta repartição? Quantos, destes, têm mais de cinco anos de serviço? Qual é o salário médio de uns e de outros? Quantos são os empregados diaristas ou jornaleiros dessa repartição? Quantos têm mais de cinco anos de serviço? Qual é a média de suas diárias? Qual é o número de operários necessários para os serviços destas oficinas? Qual é o número de empregados extranumerários [jornaleiros ou diaristas] necessários para o serviço? Para ver a discussão sobre esta matéria, ver sessão legislativa no dia 13 de dezembro de 1909, p. 763, disponível em: http://www.camara.gov.br/ 1909. O discurso de justificativa do projeto foi feita pelo deputado Alcindo Guanabara.

8 O projeto de 8 horas dos deputados Figueiredo Rocha e Rogério de Miranda não recebeu muito destaque na Câmara, não diminuindo, porém, a sua relevância. Para maiores detalhes sobre este projeto, consultar os Anais da Câmara de Deputados do Brasil, dia 27 de maio de 1912.

9 Nesse período, havia pelo menos dois sistemas teóricos bem definidos: a matriz do valor utilidade e a matriz do valor trabalho. A primeira, decorrente da tradição que remonta a Locke e Adam Smith, Benthan e Ricardo, é definida, dadas as diferenças entre estes autores, como o ato que consiste na produção de bens e serviços a serem consumidos na sociedade. A segunda, elaborada pela via marxista, a teoria do tempo de 
trabalho, considera que este é socialmente definido segundo as necessidades da reprodução e da formação de valor além do necessário àquela reprodução (Dal Rosso, 1996, p. 295-320).

10 Um dos argumentos mais usados pelos opositores a estes projetos era apontar para outros tipos de solução para as dificuldades, como controle de preços nos gêneros de primeira necessidade, através da isenção de impostos das fábricas ou importação. Ver discurso do deputado João Luiz Alves publicado nos Anais da Câmara de Deputados do Brasil, dia 14 de outubro de 1909, p. 487.

The social issue, labor and State: the view of Brazilian parliamentary elites

\begin{abstract}
The social issue as an aporetic one and a potential source for a legitimacy crisis of the capitalist system has mobilized sociological thinking and other fields such as the political and the economic. The current paper is the discourse analysis from Brazilian parliamentary elites' speeches concerning labor legislation drafts presented at the Parliament during the emergence of the twentieth century capitalism. Seventy-three speeches from Brazilian parliament members and 4,490 drafts during the period of a decade were analyzed. The social issue in Parliament politics, particularly the labor one, is seen as a relational dimension with different approaches on the role of State, the economic model and social movements.
\end{abstract}

Key-words: social issue, State, labor, parliamentary elites.

\title{
Referências bibliográficas
}

Documentos (fontes primárias)

ANAIS da Câmara de Deputados do Brasil. Disponível em <http:// www.camara.gov.br/1904 a 1914>.

BRASIL. Congresso. Câmara dos Deputados. Regimento interno da Câmara dos Deputados, 1904. Rio de Janeiro: Imprensa Nacional, 1909.

DEP. ANTONIO CARLOS. Anais da Câmara de Deputados do Brasil, Rio de Janeiro, 30 out. 1911, p. 1004. 
DEP. BARBOSA LIMA. Anais da Câmara de Deputados do Brasil, Rio de Janeiro, 30 jun. 1908, p. 627.

DEP. CALÓGERAS. Anais da Câmara de Deputados do Brasil, Rio de Janeiro, 26 jul.1912, p. 582.

DEP. GALEÃO CARVALHAL. Anais da Câmara de Deputados do Brasil, Rio de Janeiro, 14 out. 1909, p. 487.

DEP. GRACCHO CARDOSO. Anais da Câmara de Deputados do Brasil, Rio de Janeiro, 22 set. 1909, p. 428.

DEP. HOMERO BAPTISTA. Anais da Câmara de Deputados do Brasil, Rio de Janeiro, 14 out. 1909, p. 478.

DEP. IRINEU MACHADO. Anais da Câmara de Deputados do Brasil, Rio de Janeiro, 28 out. 1911, p. 271; 26 nov. 1912, p. 486.

DEP. JOÃO LUIZ ALVES. Anais da Câmara de Deputados do Brasil, Rio de Janeiro, 14 out. 1909, p. 487.

DEP. MARTIM FRANCISCO. Anais da Câmara de Deputados do Brasil, Rio de Janeiro, 26 ago. 1914, p. 559.

DEP. MONTEIRO LOPES. Anais da Câmara de Deputados do Brasil, Rio de Janeiro, 13 set. 1910, p. 290.

DEP. NICANOR NASCIMENTO. Anais da Câmara de Deputados do Brasil, Rio de Janeiro, 15 jul. 1911, p. 171.

PARECER da Comissão de Constituição e Justiça. Anais da Câmara de Deputados do Brasil, Rio de Janeiro, 1909.

PARECER da Comissão de Constituição e Justiça. Anais da Câmara de Deputados do Brasil, Rio de Janeiro, 1912.

TELEGRAMA enviado à Comissão de Constituição e Justiça pelos amigos operários do Estado da Bahia, no dia 11 de junho de 1912. Arquivo Histórico da Câmara dos Deputados. Brasil - lata 535, pasta 3, Comissão de Justiça, maço 3.

Obras citadas

BOURDIEU, Pierre. Questões de sociologia. Rio de Janeiro: Marco Zero, 1983.

- O campo econômico: a dimensão simbólica da dominação. Campinas (SP): Papirus, 2000.

CARONE, Edgar. Classes sociais e movimento operário. São Paulo: Ática, 1989. 
CARVALHO, José Murilo de Carvalho. Desenvolvimiento de la ciudadanía en Brasil. México: Fondo de Cultura Econômica, [1985], 1995.

CASTEL, Robert. As armadilhas da exclusão. In: WANDERLEY, Mariângela Belfiore; BÓGUS, Lucia; YAZBEK, Maria Carmelita (Orgs). Desigualdade e a questão social. São Paulo: EDU, 2000. p. 17-50. . As metamorfoses da questão social: uma crônica do salário. Petrópolis (RJ): Vozes, 1998.

DAL ROSSO, Sadi. Trabalho: crise e reconstrução. Sociedade e Estado, v. 11, n. 2, p. 295-320, jul./dez. 1996.

FAORO, Raymundo. Os donos do poder: formação do patronato político brasileiro. 10. ed. São Paulo: Globo, 1995. v. 2.

FAUSTO, Boris. Trabalho urbano e conflito social (1890-1920). 5 ed. Rio de Janeiro: Bertrand Brasil, 2000.

GOMES, Ângela de Castro. Cidadania e direitos do trabalho. Rio de Janeiro: Zahar, 2002.

HAGOPIAN, Frances. Traditional politics and regime change in Brazil. Cambridge: Cambridge University Press, 1996.

HOLANDA, Sérgio Buarque de. Raízes do Brasil. Rio de Janeiro: José Olympio, 1993.

MARSHALL, T. H . Cidadania, classe social e status. Rio de Janeiro: Zahar, 1967.

MARX, Karl. O Capital: crítica da economia política. Livro I, vol. I, 20. ed. Tradução de Reginaldo Sant'Anna. Rio de Janeiro: Civilização Brasileira, 2002.

MORELL, Antonio. La legitimación social de la pobreza. Barcelona: Anthropos, 2002.

OFFE, Claus. Problemas estruturais do Estado capitalista. Tradução de Bárbara Freitag. Rio de Janeiro: Tempo Brasileiro, 1984.

REIS, Elisa. Interesses agro-exportadores e contribuição do Estado: Brasil de 1890 a 1930. In: SORJ, Bernardo; CARDOSO, Fernando Henrique (Org.). Economia e movimentos sociais na América Latina. São Paulo: Brasiliense, 1985.

RANINCHESKI, Sonia. Elites parlamentares e a questão social no Brasil e no Uruguai: 1904-1914. 2004. 357 f. Tese (Doutorado em Sociologia) 
- Centro de Pesquisa e Pós-graduação sobre as Américas/UnB, Brasília. (Mimeogr.).

RANINCHESKI, Sonia; LEMOS, Leany. O perfil sociopolítico dos senadores brasileiros. Revista Senatus, Brasília, v. 1, n. 1, p. 33- 39, 2001.

RELATÓRIO da Confederação Operária Brasileira. Estudos Sociais, Rio de Janeiro, n. 18, nov. 1913.

ROSANVALLON, Pierre. A nova questão social: repensando o Estado providência. Brasília: Instituto Teotônio Vilela, 1998.

. O Estado em movimento. Sociedade e Estado, Brasília, v. 6, n. jul./dez. 1991.

SANTOS, Wanderley Guilherme do. Cidadania e justiça: a política social na ordem brasileira. 2 ed. Rio de Janeiro: Campus, 1987.

SANTOS, Fabiano. Deputados federais e instituições legislativas no Brasil: 1946-99. In: BOSCHI, Renato (Org.). Elites políticas e econômicas no Brasil contemporâneo: a desconstrução da ordem corporativa e o papel do Legislativo no cenário pós-reformas. São Paulo: Konrad Adenauer, 2000. p. 91-117.

SIMÕES, Teotônio. Os bacharéis na política: a política dos bacharéis. Tese (Doutorado em Ciência Política) - USP, São Paulo, 1983.

VIANNA, Luiz Werneck Vianna. Liberalismo e sindicato no Brasil. Rio de Janeiro: Paz e Terra, 1976.

WEBER, Max. Parlamento e Governo na Alemanha reordenada: crítica política do funcionalismo e da natureza dos partidos. Petrópolis (RJ): Vozes, 1993. 1984.

Economia y sociedad. México: Fondo de Cultura Económica, 